\title{
A filosofia da religião em David Hume: irreligiosidade e religiosidade limitadas
}

Luis Felipe Lopes

\section{Resumo}

O autor escocês defende que as crenças religiosas - em Deus, imortalidade da alma, existência de milagres, entre outras - não podem ser racionais e nem ter justificação racional, sendo que há limites severos para as bases epistemológicas da religião e seu uso na vida cotidiana. Assim, analisar a proposta humeana acerca da religião significa investigar o modo como ele fundamento sua crítica, uma vez que Hume abarca praticamente todo o escopo possível da religião em sua relação com a humanidade. A análise se baseará nas obras que contenham os argumentos principais do autor, no que tange à temática - Tratado da Natureza Humana, Investigações acerca do Entendimento Humano, Diálogos sobre a Religião Natural e História Natural da Religião - bem como uma discussão monográfica com comentadores. Desse modo, o presente trabalho tem por finalidade analisar as bases epistemológicas da crítica de Hume à religião; além do mais, apresentar uma possível proposta humeana acerca de uma "verdadeira religião", tendo em vista sua tentativa de apresentar uma ciência humana baseada em critérios seguros de investigação empírica, visando a eliminação da superstição.

Palavras-chave: empiria, ciência, religião, superstição. 


\begin{abstract}
The Scottish author defends that religious beliefs - in God, immortality of the soul, existence of miracles, among others - cannot be rational and neither have rational justification, being that it has severe limits for the epistemological basis of religion and its use in the common life. Thus, investigate the humean proposal concerning the religion means analyzing the mode as he founds his critic, once that Hume embraces all the possible scope of religion in its relation to humanity. The analysis will be founded on works that contain the main arguments of the author, with regard to the religion issue - Treatise of the Human Nature, An Enquiry concerning Human Understanding, Dialogues concerning Natural Religion and The Natural History of Religion - as well as a monographic discussion with commentators. In this manner, the present work has the purpose to analyse the epistemological basis of Hume's critique of religion; furthermore, present a possible humeam proposal concerning a "true religion", considering his attempt to present an established human science in safe criteria of empirical investigation, intending to eliminate superstition.
\end{abstract}

Keywords: empiria, science, religion, superstition.

\title{
1. Introdução
}

Tendo em vista a fundamentação de sua filosofia, Hume tem por princípio, como ele apresenta na introdução do Treatise, fundamentar a "ciência do homem", ou seja, o que diz respeito ao homem em todos os seus aspectos deve ser firmado para se evitar cair em divagações quiméricas que vão além do entendimento humano. Assim, a ciência proposta, sendo ciência de rigor que tem como base a experiência, pode analisar tudo aquilo que diz respeito ao ser humano - moral, conhecimento, religião etc.

A introdução do método experimental como critério de sua investigação e a radicalização de sua utilização - só a experiência é a fonte do conhecimento - fazem com que vários autores atribuam a Hume uma postura unicamente naturalista. Outros ainda tendem a colocar Hume como um cético ${ }^{1}$, tendo em

\footnotetext{
${ }^{1}$ Paul Russell apresenta uma breve discussão histórica sobre as várias interpretações que a filosofia de David Hume recebeu de outros filósofos. Cf. RUSSELL, Paul. The Riddle of Hume's Treatise Skepticism, Naturalism, and Irreligion. New York: Oxford University Press, 2008. Disponível em Oxford Scholarship Online <http://dx.doi.org/10.1093/acprof:oso/9780195110333.001.0001> Acesso em: 10 jun. 2009, cap. 1.
} 
vista as próprias afirmações do filósofo em suas obras ${ }^{2}$. Contudo, uma análise unívoca dessas duas posturas faz com que se perca tanto a parte crítica - para os que o vêm como naturalista - quanto a parte construtiva - para quem o interpreta como cético - da epistemologia humeana, sendo ambas fundamentais para a reconstrução mais exata da análise de Hume referente à religião.

Barry Stroud, ao comentar a tentativa de Hume de fundamentar uma nova ciência do homem, tendo em vista a experiência como fundamento, vê ai uma tentativa de revolução epistemológica e metafísica ${ }^{3}$. Stroud, claramente, sustenta que a base empírica proposta por Hume deve ser entendida como um critério científico da natureza do homem, sendo que tudo quanto for inteligível, deve sê-lo não por uma argumentação apodítica e racional, mas por meio dos sentidos. São eles que fornecem o "material" de nossos raciocínios. Assim, todo nosso conhecimento do mundo baseia-se na experiência. Isso se dá, pois o nosso modo de nos relacionarmos com o mundo depende das percepções que temos dele, ou seja, somos afetados por algo, e dependendo do grau de vivacidade, temos uma ideia ou uma impressão, sendo esta última a mais vivaz. Assim, não pode haver nenhum tipo de conhecimento que antes não tenha passado pelos sentidos ${ }^{4}$.

Fica claro que Hume tem a preocupação de que nada além da experiência possa ser o fundamento de nosso conhecimento, pois tendo em vista a revolução científica que tinha na empiria sua fonte de conhecimento e na experimentação seu critério, como fundar uma ciência do homem de forma apodítica e puramente racional? Seria um contrassenso supor uma ciência que prescinda da

${ }^{2}$ Destaca-se sua discussão sobre o ceticismo radical e o acadêmico - cf. HUME, David. Investigação sobre o Entendimento Humano. São Paulo, SP: Abril Cultural, 1973 [1748]. Coleção Os Pensadores, vol. 22, secção XII -, onde Hume aponta claramente para a importância do uso do segundo para se evitar cair em superstições, bem como a discussão na Parte I dos Diálogos cf. HUME, David. Diálogos sobre a Religião Natural. In: Obras sobre Religião. Lisboa: Fundação Calouste Gulbenkian, 2005 [1779], parte I - entre Cleantes e Fílo sobre a influência do ceticismo e sua importância e ainda as discussões do Livro I, Parte IV, secções I e II do Treatise - cf. HUME, David. The Treatise of Human Nature. London, UK: Penguin Classics, 1985 [17391740], Livro I, Parte IV, secções I e II.

3 "This "revolutionary" view completely reverses the traditional conception of the human nature. According to the ancient definition, man is a rational animal. He therefore fully realizes his true nature, or fully expresses his essence, only in so far as he controls his life and thought by reason (...) Hume's theory sees every aspect of human life as naturalistically explicable. It places man squarely within the scientifically intelligible world of nature, and thus conflicts with the traditional conception of a detached rational subject" (STROUD, Barry. Hume. London, UK: Routledge \& Kegan Paul Ltd, 1977, p.11-13).

${ }^{4}$ Cf. HUME, The Treatise..., p.52-53. 
experiência. Desse modo, Hume estabelece a base de toda sua teoria, um critério que irá nortear toda sua análise: o que for afirmado que existe ou que é cognoscível e que não for experienciado ou é uma quimera ou uma ilusão ou ainda uma operação da imaginação. Esta fundamentação pode ser descrita como uma fundamentação naturalista, pois toda a construção do conhecimento pode ser remontada a partir de critérios naturais da experiência comum, mesmo as faculdades da mente, tais como imaginação, memória e outras operações mentais. Nesse sentido, Hume pretende, apontar os limites do conhecimento humano, para evitar que a investigação humana extrapole a empiria.

Jonathan Bennett, em seu livro Learning from six Philosophers, no segundo volume, apresenta uma afirmação um tanto quanto controversa: "Hume, algumas vezes, é descrito como cético acerca da causalidade, mas isto é errado" " O problema é que essa construção diz respeito a apenas um passo da filosofia de Hume e não pode ser tomado como um todo. Bennett, de fato, não afirmou nada de errado, pois Hume não é um cético quanto a causalidade, contudo seria mais correto afirmar que Hume não é só, mas também, um cético acerca da causalidade e também acerca da construção do conhecimento. A afirmação de Bennett parece indicar uma contraposição àqueles que tomam Hume como um cético radical ${ }^{6}$, sendo possível de ser entendida apenas como uma ressalva.

$\mathrm{O}$ ceticismo de Hume diz respeito à tentativa de apresentar limites à investigação humana. Não é um ceticismo estéril, radical, hiperbólico, hipotético $^{7}$; mas uma apresentação das possibilidades do conhecimento ${ }^{8}$. O filósofo escocês deixa clara sua inclinação pelo estilo de ceticismo que seja moderado, para que os nossos juízos possam ter a clareza daquilo que pode ou não ser objeto do conhecimento. Ele quer se livrar de dois tipos de juízos acerca do mundo: os abstrusos/obscuros ${ }^{9}$ e os radicalmente céticos ${ }^{10}$, tendo em vista seu projeto científico, pois Hume não pretende que suspendamos o juízo acerca do mundo ou acerca de nossa ação diária, mas quer que tanto nosso entendi-

\footnotetext{
5 "Hume is sometimes described as a sceptic about causation, but that is wrong" (BENNETT, Jonathan. Learning from six Philosophers. Vol. 2. USA: Oxford University Press, 2003, p. 276).

${ }^{6}$ Cf. RUSSELL, The Riddle..., p. 3-8.

${ }^{7}$ Hume apresenta, notadamente, uma crítica ao pirronismo e à proposta cética de Descartes do

Discurso do Método.

${ }^{8}$ Cf. HUME, Investigação..., p. 191.

${ }^{9}$ Cf. HUME, The Treatise..., pp. 41-42 e 507; HUME, Investigação..., seção I.

${ }^{10}$ Cf. HUME, The Treatise..., pp. 237-238; HUME, Investigação..., p. 195.
} 
mento quanto nossa ação sejam fundamentados em critérios seguros ${ }^{11}$; além de pretender uma fundamentação de nossa razão na "vida comum"12 e limitar as investigação humana.

Ora, esses tipos de raciocínios são questões de fato, sendo possível pensar sua negação como não existente, enfatizando aqui o critério de verificação empírica, como foi tratada na primeira parte deste capítulo. O problema está no fato de haver raciocínios que extrapolam os limites do entendimento humana, indo além da fundamentação empírica. Isso gera confusão e acarreta em contradição, uma vez que sua força é pequena, devido ao afastamento em relação aos sentidos, pois lembremos que uma ideia se torna mais vivaz quanto mais próxima da impressão que se lhe assemelha, e não tem influência na vida cotidiana ${ }^{13}$. Todavia, o que é mais seguro é mais natural, logo, mais próximo do que vivemos de fato ${ }^{14}$.

Que Hume pretende romper com qualquer tipo de raciocínio supersticioso, isto é claro em toda sua obra. Sendo assim, sua intenção é apresentar um conhecimento com rigor de ciência, cujos fundamentos sejam bem sólidos. Como já fora dito, esse tipo de raciocínio - sólido - não pode estar ligado à religião de forma alguma, por se tratar de um tipo de conhecimento que tenta lidar com questões que estão além de nossas capacidades. Nem mesmo uma genealogia da religião apresenta qualquer forma de justificação para sua tentativa investigativa obscura e abstrusa, fazendo com que Hume associe qualquer uma dessas tentativas de justificação da religião a um tipo de superstição. Nesse sentido, o filósofo escocês apresenta críticas às tentativas da religião de justificar alguma de suas crenças como sendo racionais e demonstráveis ou ainda autoevidentes.

Tendo sido fundamentada a epistemologia, pode-se agora expandir a investigação sobre todos os outros aspectos da natureza humana, pois, como Hume faz notar na introdução do Treatise, fundamentar a ciência da natureza

\footnotetext{
${ }^{11}$ Cf. HUME, The Treatise..., pp. 196-197.

${ }^{12}$ Cf. HUME, Investigação..., seção XII. Gaskin afirma que, para Hume, a prática cotidiana é um remédio contra o ceticismo radical, sendo que as crenças naturais são as crenças da vida prática. Cf. GASKIN, J.C.A. Hume's Philosophy of Religion. 2 ed. London: The Macmillan Press Ltd., 1988, pp. 126-129.

${ }^{13}$ Esses raciocínios obscuros/abstrusos são considerados como ingênuos por Hume, pois ele mesmo afirma que os filósofos muitas vezes não se diferenciam do vulgo em relação a algumas crenças. Supor crer que haja um Ente que tudo sustenta é uma crença do vulgo que os filósofos tentam justificar de modo obscuro, sendo, portanto, uma superstição.

${ }^{14}$ Cf. HUME, The Treatise..., pp. 320-321.
} 
humana é um ponto fundamental para se desenvolver uma investigação de rigor em várias áreas, dentre as quais o presente trabalho destaca a religião. Ora, a religião é o principal alvo de ataque de Hume, pois grande parte das doutrinas que envolvem raciocínios abstrusos, para Hume, tanto na metafísica, como na própria moral, decorrem de uma influência religiosa ${ }^{15}$, o que é pernicioso para a investigação humana e para a ação humana.

Neste sentido, a crítica à religião apresenta os mesmos aspectos da crítica aos fundamentos não empíricos do conhecimento, bem como os mesmos critérios de verificação, ou seja, há aspectos que apontam a limitação da religião - em sentido explicativo, acerca dos fundamentos de suas crenças e sua influência sobre a ação humana -, assim como há aspectos que apontam para como se deveria falar sobre a religião - se há uma religião revelada ou se é um processo natural, se as crenças podem ou não apresentar fundamentos de rigor científicos.

\section{Críticas às provas da existência de Deus}

Um dos principais problemas abordado por Hume é a análise das provas da existência de Deus de que ele tinha conhecimento ${ }^{16}$ no século XVIII, ou seja, fazendo parte de uma época em que o debate entre os filósofos religiosos e os filósofos ateus ${ }^{17}$, para usar uma nomenclatura de Paul Russell, permeava a academia de então. Hume estava a par de toda tentativa racional das provas da existência de Deus - como de Descartes, Clarke e Locke -, bem como conhecia o debate entre os filósofos que na época recebiam o nome de ateus ${ }^{18}$ por negarem, de algum modo, a existência de um Deus, particularmente Spinoza e Hobbes.

\footnotetext{
${ }^{15}$ Cf. HUME, The Treatise..., Livro II, Parte III, Secções I e II.

${ }^{16}$ É importante notar que Hume tem acesso a um debate acerca das provas da existência de Deus que se apresentavam em seu tempo. Russell, no The Riddle of Hume's Treatise, apresenta um histórico interessante sobre o debate acerca dos tipos de provas da existência de Deus no meio intelectual que Hume fazia parte, onde se destacam as provas a priori de Clarke e seus seguidores - em especial as Boyle`s Lectures -, bem como a tentativa de Locke de uma prova comológica. Cf. RUSSELL, The Riddle...,pp. 28-34.

${ }^{17}$ Essas nomenclaturas - religiosos ou teístas e ateus - será melhor esclarecida e discutida mais à frente.

${ }^{18}$ Russell faz notar que havia algumas denominações para esse tipo de filósofo que negavam a existência de Deus como os teístas a propunham, a saber: minute philosopher, freethinker, panteistas, etc. (cf. RUSSELL, The Riddle..., pp. 18 e 45).
} 
Cabe, então, a pergunta: por que se preocupar com uma noção que para ele é tão problemática? Este é o ponto, conceber um Ente que esteja além dos sentidos, mas que pode ser percebido através da experiência e, partindo da analogia, conceber que de fato Ele existe ou ainda, conceber um Ente cuja existência pode ser demonstrada racionalmente, parece muito ilusório e supersticioso, tendo em vista o fundamento da sua filosofia. Se a existência de Deus pode ser demonstrada pela razão, a ideia de Deus deve compartilhar as mesmas características das outras ideias próprias das questões de razão. Contudo, se a existência de Deus requer uma prova através da experiência, esta é uma questão de fato e deve ter as características próprias a tais questões. Analisemos, pois, a argumentação humeana referente ao primeiro tipo de prova da existência de Deus, a saber: a prova a priori.

Toda questão que diz respeito à razão deve ser uma questão demonstrativa ou intuitivamente afirmada e cuja demonstração não tenha relação com sua existência no mundo, além do que, esta mesma demonstração deve ser irrefutável ${ }^{19}$, ou seja, para que uma ideia seja uma questão de razão não é possível pensar sua negação sem cair em contradição, uma vez que não recorremos à natureza (sentidos), mas investigamos constructos humanos. Por exemplo, não é possível conceber um círculo quadrado, não porque não haja tal objeto no mundo perceptível por nós, mas porque sua definição não o permite. Ora, deste modo, a ideia de Deus como alguém ou algo existente deve ser impossível de ser negada sem incorrer em contradição para que se aceite uma prova a priori da existência de Deus. Hume tem em mente, segundo Russell, as provas cosmológicas de Locke, Clarke, Baxter e Cutworth ${ }^{20}$ e coloca essa posição de modo mais claro nas falas de Demea, que é tido, pela maioria dos comentadores, como o físico newtoniano do argumento a priori ${ }^{21}$. Contudo, a base da crítica a esse tipo de argumento começa a ser construída no Treatise.

Para que seja impossível negar a existência de Deus, é necessário que sua existência seja necessária, pois só assim, sua negação incorre em contradição. Hume, ao falar sobre a existência ${ }^{22}$, afirma que esta só pode ser pensada uma vez que se tenha a experiência do objeto, ou seja, não há uma qualidade distinguível que possa ser aplicada a outro objeto, pois uma vez percebido, este objeto

\footnotetext{
${ }^{19}$ Cf. HUME, The Treatise ..., pp. 136-138.

${ }^{20}$ Cf. RUSSELL, The Riddle..., pp. 114-119.

${ }^{21}$ Cf. SESSIONS, William L. Reading Hume 's Dialogues: a veneration for true religion. Bloomington, USA: Indiana University Press, 2002, pp. 26-27; GASKIN, Hume's Philosophy..., pp. 159-166.

${ }^{22}$ HUME, The Treatise..., Livro I, Parte II, Secção VI.
} 
deve ser percebido como existente. Hume dá um primeiro passo para recusar qualquer tipo de prova a priori, pois para provar a existência de Deus, deve-se recorrer, então à experiência para saber se ela corrobora tal afirmação: Deus existe, pois, sendo Deus percebido, Ele o será como existente. Não apenas isto, ao falar sobre o conhecimento e a probabilidade ${ }^{23}$, o filósofo escocês afirma que as provas "são (argumentos) derivados da relação de causa e efeito" ${ }^{24}$, ou seja, esse tipo de raciocínio que se apresenta como prova não pode ter sua base em relações de ideias, mas somente em questões de fato, fazendo com que qualquer argumento cosmológico perca sua eficácia para Hume. Gaskin ${ }^{25}$ afirma que a crítica de Hume é apresentar que qualquer tipo de argumento cosmológico é sem sentido, ou seja, Hume afirma que a prova a priori é uma disputa verbal que não faz sentido sem termos a experiência do objeto real, uma vez que necessidade não é um qualidade de seres de fato, como fora visto no capítulo primeiro.

Outro aspecto é que, uma vez que uma prova é baseada na relação de causalidade e esta, como Paul Russell faz notar - apontando que a interpretação de que o Treatise não é uma obra também sobre a religião é incorreta -, não comporta a ideia de necessidade. Percebe-se que, como não é possível conceber a ideia de existência como algo necessário, não é possível que haja contradição em sua negação. Logo, mesmo que Deus exista ${ }^{26}$, Sua existência não pode ser provada a priori.

Outra crítica que Hume apresenta no Treatise está ligada ao fato de que não somos obrigados a supor que toda causa tem um efeito ${ }^{27}$. Desse modo, não é necessário que suponhamos haver uma causa para todas as coisas, como afirmam aqueles como Clarke e Locke que querem defender a ideia de que tudo o que existe tem uma causa e o efeito é adequado a esta causa. Assim, não há contradição em se negar que o mundo não tenha uma causa para sua existência, pois não há nenhum problema neste tipo de raciocínio ${ }^{28}$.

\footnotetext{
${ }^{23}$ HUME, The Treatise..., Livro I, Parte III, Secção XI.

${ }^{24}$ Ibid., p. 175.

${ }^{25}$ Cf. GASKIN, Hume's Philosophy..., pp. 68-73.

${ }^{26}$ Cf. HUME, op. cit., p. 142.

${ }^{27}$ Cf. HUME, The Treatise..., p. 126.

${ }^{28}$ A adequação do efeito à causa é apresentada por Hume, nos Diálogos, como um argumento teleológico. O que queremos mostrar é que essa crítica é também uma limitação à existência de um argumento a priori. Também fica mais claro que a afirmação de Russell de que o Treatise não seja uma obra tão alheia à religião toma mais fundamento, uma vez que grande parte da discussão da mesma obra traz grandes consequências à religião. Russell argumenta que Hume não fez isto por acaso, pois os próprios contemporâneos do filósofos atribuíam à sua obra um caráter antirreligioso.
} 
Hume retoma toda esta argumentação na parte IX dos Diálogos. Demea, após uma longa discussão acerca do argumento do desígnio, propõe que, de fato, só há uma maneira de provar que Deus existe: através do argumento a priori $^{29}$. Demea o formula nos termos de que tudo tem uma causa, sendo necessário que nada surja do nada, logo, o mundo tem uma causa para garantir sua existência, sendo essa causa uma divindade. O próprio Cleanto se contrapõe, afirmando que essa questão não é questão de razão, mas de fato, pois a negação desse argumento não implica em contradição. Deste modo, supor uma existência necessária, continua Cleanto, é um absurdo, pois nossas faculdades dos sentidos não concebem a ideia de algo necessário. Fílon acrescenta que a própria ideia de necessidade é contrária à religião. Nesse sentido, para $\mathrm{Hume}^{30}$, a prova sem a experiência não tem qualquer fundamento epistemológico e científico, dizendo respeito, nos dizeres de Fílon, às "pessoas de capacidade metafísica que se habituaram a si mesmas ao raciocínio abstracto" 31 .

E quanto à prova a posteriori? Há de fato alguma diferença em aceitá-la em detrimento à prova a priori ou Hume despreza os dois tipos de prova? Fílon afirma no último capítulo dos Diálogos que, em alguma medida, é possível, ou melhor, é mais coerente uma tentativa de prova que se baseie na experiência, mas isso não quer dizer que seja totalmente possível provar que Deus existe. O ponto de Fílon é apenas enfatizar o uso de argumentos por analogia - mesmo com ressalvas a essas analogias - ao invés de provas demonstrativas. Tendo em vista que Fílon é tido pela quase unanimidade dos comentadores como o porta-voz principal de Hume - apesar de termos visto que Cleanto também defende algumas teses de Hume em alguns momentos -, pode-se afirmar que essa seria a posição de Hume. Aqui não analisaremos a parte afirmativa da teoria de Hume sobre o possível uso das analogias, mas, em primeiro lugar, apontaremos para os limites deste uso. Vejamos, então, qual tipo de argumento a posteriori o filósofo tem em mente ao investigá-lo e como ele procede com tal investigação.

\footnotetext{
${ }^{29}$ Cf. HUME, Diálogos sobre..., p. 87.

${ }^{30}$ Vale notar que acerca do que representa cada personagem nos Diálogos, há um certo consenso de que Fílon fala por Hume, mas não como único porta-voz, pois Cleanto também traz afirmações que são próprias de Hume, como neste caso da crítica ao argumento a priori. Cf. O 'CONNOR, David. Hume on religion. London, UK: Routledge, 2001, pp. 214-216.

${ }^{31}$ Cf. HUME, op. cit. p. 92.
} 
Este $^{32}$ afirma que, utilizando das regras de inferências, podemos ao analisar o mundo e perceber que assim como há um design na construção de um artefato humano - uma máquina, por exemplo -, ou seja, supõe-se uma inteligência que faça com que aquele objeto possa surgir; do mesmo modo supõe-se que há uma inteligência, proporcional ao efeito, que seja autora do mundo, uma vez que o mundo deve ter uma causa. Aqui há o uso da doutrina, já comentada, de que tudo deve ter uma causa, pois nada no mundo pode ser causa sui, além de que nada pode ter surgido do nada sem qualquer inteligência, sendo que a matéria não pode ter em si seu princípio organizador ${ }^{33}$. Desse modo, o princípio organizador deve estar fora da matéria, assim como supomos que o princípio organizador de uma casa ou de outro artefato qualquer não esteja na casa ou no artefato, mas na mente de quem o faz, de seu autor.

Fílon objeta que a inferência da parte para o todo sem qualquer costume ou hábito perde força, pois, como vimos na causalidade, é o raciocínio que liga as partes não conjugadas, tendo em vista o hábito passado, ou seja, sem hábito não seria mais provável dizer que o sol vai nascer amanhã do que dizer o sol não vai nascer amanhã. $\mathrm{O}$ mesmo se aplica à prova a posteriori, pois, quando inferimos a partir de artefatos humanos, de fato, temos a experiência que nos ajuda na inferência e analogia, mas Deus é um ser único que fez um ato único de criar as $\operatorname{coisas}^{34}$, logo, não temos o costume para fortalecer essa inferência, assim, afirmar que Deus é o autor do mundo ou que há uma inteligência análoga à humana, não é mais certo que negar isso. Além do mais, não fica claro que tipo analogia há entre o mundo e o homem para se inferir tal inteligência, pois por que privilegiar a inteligência a outras coisas? ${ }^{35}$ Cleanto tenta responder afirmando que a ciência também faz uso de fatos distantes e analogias não propensos a serem fundados em costumes e que arbitrariamente confiamos mais neste tipo de afirmação científica do que na religiosa ${ }^{36}$, a que Fílon objeta que as proposições e analogias científicas têm sentido e as religiosas são discrepantes.

\footnotetext{
32 Para fins de investigação, será apresentado o debate dos Diálogos em nome de seus respectivos "atores", mas tendo em vista que Fílon - praticamente sempre - e Cleanto - algumas vezes que serão indicadas - falam por Hume. Já Demea e o mesmo Cleanto - este nas vezes que for indicado - caracterizam a posição contra a qual Hume tenta debater, uma vez que se fará uma reconstrução do argumento.

${ }^{33}$ HUME, op. cit. p. 29.

${ }^{34}$ Fílon toma isso como hipótese: suponhamos que Deus fez o mundo; Ele o fez uma única vez.

${ }^{35}$ Cf. HUME, Diálogos sobre..., pp. 25-34.

${ }^{36}$ Ibid., p. 35-49.
} 
Cleanto tenta apresentar, então, algumas "correções" ao seu argumento: a analogia é possível se há um ajuste entre causas e efeitos - um efeito racional tem uma causa racional -, assim, por exemplo, a harmonia seria uma prova do design, por não ser intrínseca ao mundo ou ainda uma voz articulada só pode vir de uma inteligência, logo, de uma coisa infere-se a outra. Não lhe interessa saber se Deus tem ou não causa, mas que Ele é causa. Contudo, o próprio Fílon e também Demea lhe contrapõem. Demea argumenta a favor de uma prova a priori, afirmando que assim Cleanto abusa de antropomorfismos e que concebe um Deus múltiplo como nós e não uno. Já Fílon aponta para os limites da investigação humana, ou seja, grande parte de sua crítica se baseia na perspectiva cética de Hume. Por que multiplicar entidades se podemos, então conceber uma ordem inerente à própria matéria ao invés de extrapolarmos em direção a algo fora do mundo, neste caso um Deus, pois, por analogia, se Deus é auto-ordenado, o mundo também o é? ${ }^{37}$ Uma vez que nossa percepção é limitada, não podemos ter acesso ao universo como um todo para saber se nossa inferência perde ou ganha força ${ }^{38}$; além do mais a experiência não garante que haja só um Deus, mas que poderia haver vários ${ }^{39}$; como o mundo parece mais com um organismo que um artefato, é mais plausível pela experiência inferir por uma divindade como a alma de um corpo ${ }^{40}$ supor várias teogonias de animais ou vegetais - orgânicas ou ainda supor várias cosmogonias esdrúxulas - como, por exemplo, matéria finita com transposições finitas numa duração eterna, etc. O problema que Hume aponta, pela boca de Fílon, é que se de um lado o argumento a priori não pode ser usado na prova da existência de um ordenador do mundo, como vimos, a prova pela experiência, apesar de poder ser usada, gera resultados mirabolantes, pois, como nossos sentidos são limitados, não há garantias sólidas para as inferências. Fílon chega a afirmar que o cético, o teísta e o politeísta estão no mesmo nível de explicação, pois pelas regras de analogia muita coisa se segue sem que haja privilégio para qualquer uma das posições religiosas ou filosóficas.

No Treatise ${ }^{41}$, Hume já afirmava, contra Descartes, que não há como, pela verificação empírica, afirmar que há um Deus que intervenha no mundo

\footnotetext{
${ }^{37}$ Ibid., pp. 49-53.

${ }^{38}$ Ibid., pp. 56-59.

${ }^{39}$ Vários deuses atrapalhados que criam por tentativa e erro ou ainda que esse mundo é o melhor dentre tantas tentativas etc. Ibid., pp. 59-62.

${ }^{40}$ Ibid., pp. 62-66; 74-80.

${ }^{41}$ Cf. HUME, The Treatise..., pp. 200-202.
} 
de modo a ordená-lo, pois não há como termos uma impressão que produza tal ideia, sendo, portanto, uma inferência sem força. Tanto Gaskin ${ }^{42}$ quanto Sessions $^{43}$ afirmam que o que Hume quer enfatizar, não é que não haja uma ordem ou possivelmente um ordenador, mas que não há privilégio para um ordenador inteligente ou intervencionista. Ao final da Parte VIII, Cleanto objeta que as hipóteses de Fílon são completamente inconcebíveis e problemáticas, ao que Fílon consente. Contudo, este reafirma que sua preocupação não é mostrar que não haja certo arranjo no mundo, mas que tudo que se afirma com base na verificação empírica é problemático, assim como as suas próprias posições, o que faz com que, nesta matéria, ele prefira o ceticismo ${ }^{44}$.

Hume aponta claramente para sua preocupação com os limites da investigação humana, uma vez que, em se tratando de questões de fato, não pode haver concepções demonstrativas nem ideias que não tenham impressões que se lhe assemelhem. Apesar de indicar a possibilidade do uso da inferência neste tipo de questões, Hume limita sua utilização, restringindo as justificativas epistemológicas e metafísicas da religião acerca das provas da existência de Deus, ou seja, não há justificação epistêmica tanto racional - a priori quanto empírica - a posteriori - para se afirmar, com certeza, que há um Deus que intervenha no mundo, pois, como vimos, da experiência tudo se segue. Do mesmo modo, não temos como saber quais são seus atributos, pois não temos certeza de qual a proporção exata da analogia entre os atributos do mundo, captados pelos sentidos, e os do seu criador, inferido pela analogia.

Outro problema fundamental está no fato de que se a empiria for o critério de fundamentação da prova da existência de Deus, parece haver uma incompatibilidade entre o mal no mundo e um ordenador com os atributos referidos.

Fílon quer mostrar ${ }^{45}$ é que pela inferência - a partir do mundo como ele existe: cheio de males naturais, físicos, espirituais - é impossível compatibilizar a existência de um Deus com os atributos de uma analogia pretendida por Cleanto. Assim, se Deus é o autor de tudo e se há males no mundo, ou Ele não é onipotente, ou Ele não é infinitamente bom ou ainda não é nenhuma dessas duas coisas ${ }^{46}$. Sendo assim, há um limite sério para tal analogia, como Fílon aponta no texto: "estes assuntos ultrapassam toda a capacidade humana", pois

\footnotetext{
${ }^{42}$ Cf. GASKIN, Hume 's Philosophy ..., , pp. 36-39.

${ }^{43}$ Cf. SESSIONS, Reading Hume's Dialogues..., p. 131.

${ }^{44}$ HUME, Diálogos sobre..., p. 86.

${ }^{45}$ HUME, Diálogos sobre..., p. 106.

${ }^{46}$ Hume, através de Filon, recupera a crítica de Epicuro. Cf. Ibid., pp. 102.
} 
se Deus fosse infinitamente bom ${ }^{47}$ : não deveria haver um mínimo de mal; deveria haver uma distribuição pródiga dos poderes e faculdades; não haveria uma estrutura natural que gerasse a dor em nós; compreenderíamos suas razões por volições particulares e não haveria qualquer tipo de intervenção, pois isto caracteriza um retoque no mundo incompatível com uma obra de um Deus perfeito ${ }^{48}$.

Cleanto tenta minizar a crítica afirmando que podemos conceber um Deus finitamente bom que permita o mal tendo em vista um bem maior e posterior. Fílon responde que se Deus for mais modesto, por que não fez um mundo mais modesto. Deste modo, pela inferência só se pode levantar quatro hipóteses sobre a causa do mundo: 1) dotada de perfeita bondade; 2) dotada de perfeita malícia; 3) tem bondade e malícia ou 4) não tem nem uma nem outra. Fênomenos que contenham mistura de bem e mal negam as duas primeiras hipóteses e a uniformidade das leis nega a terceira hipótese, sobrando apenas a quarta ${ }^{49}$ que é incompatível com os atributos pretendidos por Cleanto. Assim, é mais coerente supor haver uma causa "cega", sem propósito de nada, tendo em vista tantos males ${ }^{50}$ existentes, pois assim, suporíamos um princípio apenas de conservação da humanidade sem preocupação com a felicidade dos homens. O mesmo raciocínio é aplicado ao mal moral, pois tendo em vista tantos vícios e a inclinação a eles, como pode ser Deus fonte de uma moralidade ${ }^{51}$ Sessions afirma que apelando para a experiência, Cleanto põe em dúvida, inclusive, os atributos morais divinos, retirando da Divindade qualquer acepção moral ${ }^{52}$.

Para Gaskin ${ }^{53}$, a conclusão de Hume é que estaríamos forçando o entendimento, pela inferência, ao tentar supor uma boa intenção divina em meio a tantos males. Assim, mesmo a teodicéia de Demea é atingida pela crítica de Fílon, pois supor haver um grande plano divino não fortalece a analogia, fazendo com que a inferência perca ainda mais força. Neste sentido, a conclusão de Hume é que estas provas a posteriori ferem as regras do conhecimento humano, pois epistemologicamente e metafisicamnete não há fundamentos seguros para garantir tal tipo de conhecimento. Mais uma vez, Hume insiste

\footnotetext{
${ }^{47}$ Para uma descrição mais detalhada destas 4 objeções, vide Secção XI dos Diálogos.

${ }^{48}$ Hume defende esta mesma tese da intervenção como sendo prova de um mundo não perfeito nas Investigações, Secção VII. Por que Deus não fez o mundo já pronto para evitar retoques?

${ }^{49}$ Cf. HUME, Diálogos sobre..., pp. 122-123.

${ }^{50}$ Ibid., pp. 100-104.

${ }^{51}$ Ibid., pp. 123-125.

${ }^{52}$ Este tema será melhor discutido no próximo subitem.

${ }^{53}$ Cf. GASKIN, Hume 's Philosophy ... , pp. 45-46.
} 
não que não haja um Deus - coisa que Gaskin e Sessions também afirmam -, mas que as tentativas de provar sua existência estão além de qualquer racionalidade ou fundamento científico, por isso Hume afirma preferir ficar com o ceticismo, pois este se apresenta mais coerente, uma vez que a filosofia deve se afastar das superstições da religião, pois não há nada de racional na religião, como pretendem os religiosos ${ }^{54}$.

\section{Moral sem Religião}

Hume, no Livro III do Treatise, apresenta uma teoria acerca da moral, que está associada ao jusnaturalismo de então. Neste sentido, sua construção visa romper com a interpretação religiosa da moral e da política, tentando estabelecer uma construção puramente natural, ou seja, humana. Deste modo, vale notar os aspectos críticos que apontam para a limitação do uso da religião como fundamento da ação moral e mesmo da ação e constituição política, propósito desta discussão.

Primeiramente, é necessário apresentar e relembrar alguns pontos basilares para Hume. Uma ideia tem uma impressão que se lhe assemelha; a semelhança facilita qualquer tipo de transição entre ideias e impressões, inclusive gerando vivacidade; a razão não pode nos influenciar em nada nas ações; os sentimentos - dor e prazer, por exemplo - são princípios básicos que regem muitas de nossas decisões.

Acerca dos dois primeiros pontos, nada a acrescentar, mas cabe uma elucidação dos dois últimos que são imprescindíveis para a crítica humeana à religião. Quanto ao fato dos sentimentos serem princípios básicos na decisão de ações, Hume quer mostrar que estes influenciam-nos no surgimento em nós do prazer ou da dor em relação a uma ação. Assim, associamos uma determinada prática com a felicidade ou com a tristeza. Já o que diz respeito ao fato da razão não nos influenciar, mas somente as paixões, Hume quer mostrar que apenas uma impressão pode gerar em nós uma atitude volitiva, uma vez que a razão só age por demonstração e como nossas ações são questões relativas a nossa experiência com o mundo, não é possível que um raciocínio nos conduza a fazer $\operatorname{algo}^{55}$. Outro motivo é o fato de mesmo que a razão pudesse

\footnotetext{
${ }^{54}$ Hume chega a afirmar que a religião é uma filosofia, logo, não pode ir além da experiência e da razão e dar saltos inferenciais. Cf. HUME, Investigações..., pp. 184-185 e 190-191.

${ }_{55}$ Para um melhor desenvolvimento dessas ideias cf. HUME, The Treatise..., pp. 460-461; $462-463 ; 510 ; 511 ; 515-519$.
} 
nos influenciar, a força de suas ideias - a vivacidade - é muito menor que a vivacidade das impressões, por aquelas serem cópias desta. Com isso, Hume rompe com a tradição moral e ética tanto cristã quanto grega de uma moral/ ética racionais, o que acarreta em uma limitação cara acerca do que influencia nossas ações, fundamentando os princípios morais sob um senso natural e um senso artificial. Hume explicita a junção desses dois princípios quando afirma que a razão não pode gerar em nós o sentimento de bem ou de mal, mas que somente o mérito e o demérito - que são sentimentos - podem influenciar-nos numa conduta natural.

Ora, esses princípios enunciados por Hume apresentam uma crítica muito grande à religião, pois esta parte do princípio de que a ações morais boas e ruins são demonstráveis, tendo em vista haver um Deus que é a medida destas atitudes. Assim, para que essa relação moral pudesse ser demonstrável, logo, imutável - pois aquilo que e demonstrável não permite sua negação sem incorrer em contradição -, deveria haver uma relação de necessidade entre a vontade e a ação, mas não existem relações necessárias de caráter demonstráveis em questões de fato, fazendo com que, deste modo, as relações morais sejam contingentes, logo, construídas pelos homens.

Talvez se pudesse objetar que o conhecimento nas doutrinas cristãs influenciam as atitudes humanas, por exemplo: conhecer que há um Deus e que há um céu ou um inferno fazem com que eu prefira agir moralmente bem do que agir moralmente mal. Hume responde a isto, afirmando que as doutrinas, na verdade, em vez de nos influenciar por causa do conhecimento, fazem-no devido as impressões que geram em nós, sendo que essa geração de impressões (paixões) em nós não é feita propriamente pela razão, mas por situações a elas conexas. O que Hume tenta empreender acerca da moral é mostrar que não podemos fundamentá-la a não ser na empiria; não podemos procurar fundamentos das ações morais ou acrescentar-lhes qualidades que não são verificadas empiricamente.

Assim, seu projeto moral não prevê a existência de um Deus para sua justificação, pois tudo quanto for relativo à prática humana será fundamentado naqueles três princípios: tudo começa na impressão, a semelhança facilita a transição e a razão não pode influenciar nossa conduta. Ora, quais seriam, então as justificativas da moral?

Russell afirma que Hume apresenta uma perspectiva artificial - feita pelos homens - e natural - impulsos originários - que regem tal assunto. Assim, não há mandamentos necessariamente obrigatórios que não variam com o tempo, 
como vimos, pois a experiência não o comprova. O que esta pode mostrar é que há sistemas morais de acordo com a época, as circunstâncias e lugares ${ }^{56}$, uma vez que a moral diz respeito às relações internas com objetos externos. Mas, por quê?

Somos naturalmente inclinados a viver em comunidade, pois uma vez que somos também de natureza egoísta, precisamos do governo para buscarmos uma ordem para nossa convivência. Essa ordem é buscada pelo fato do ser humano perceber que está ligado à virtude um sentimento de prazer e ao vício um sentimento de dor, pois socialmente é melhor que todos nos respeitemos do que haver disputas de ego. Neste sentido, fica claro que o fundamento de uma decisão pela vida política está na impressão que nos causa um acordo anterior. Por exemplo: os homens decidem que uma prática será adotada e percebem que tal adoção gerou um sentimento de prazer a todos. Deste modo, todos têm aquilo por virtuoso - sendo o virtuoso aquilo que gera em nós um sentimento agradável - e justo. Assim, a justiça é uma construção artificial, enquanto o vício e a virtude relacionam-se com uma impressão. Deste modo, Hume não abre espaço a não ser para uma influência empírica sobre nossas ações, o que reduz o escopo da religião, que tinha como uma de suas pretensões, auxiliar os homens em suas ações. Na última secção dos Diálogos, Hume (Fílon) chega a afirmar que a religião causa mais egoísmo - por exemplo, quando se busca a vida eterna, esquece-se da vida social "aqui na terra" -, ocasionando muitos males à sociedade, sendo que a verdadeira religião não deveria se preocupar com este tipo de coisa. No máximo, a religião serve à política como modo de adestramento $^{57}$. Gaskin $^{58}$ também afirma que muitas das virtudes religiosas nem são úteis à vida social, inclusive, causando-lhes oposição: "ou se serve a Deus ou se serve à moral”, como no caso da transformação do homem em um ser passivo - nos dizeres de Hume, citando Maquiavel ${ }^{59}$.

Paul Russell afirma que Hume está no meio termo entre o ceticismo e o naturalismo, pois sua tentativa é crítica e limitadora para questões que extrapolam a convenção humana, logo, além do natural. Isso inclui uma diminuição do escopo da religião na vida humana em geral, até mesmo sendo um modo

\footnotetext{
${ }^{56}$ Para um melhor desenvolvimento dessas ideias cf. HUME, The Treatise..., pp. 449-450; 516-519; 585-586.

${ }^{57}$ Cf. HUME, Investigações..., pp. 190-191.

${ }^{58}$ Cf. GASKIN, Hume's Philosophy ..., , pp. 151-153.

${ }^{59}$ Cf. HUME, David. História Natural da Religião. In: Obras sobre Religião. Lisboa: Fundação Calouste Gulbenkian, 2005 [1757], pp. 198-200.
} 
de mitigar a crença na existência do próprio Deus, uma vez que sua "função" apresenta limitações importantes num mundo em que a moralidade é autônoma e a natureza funciona com base em leis uniformes. A religião seria uma construção baseada na experiência humana cuja justificação se fundamenta nas impressões e na convenção - aspectos naturais e/ou artificiais - sempre ligadas à experiência da vida comum.

Conclui-se, então, por uma moral sem religião, o que acarreta uma limitação importante para a religião, pois, como afirmam Cleanto ${ }^{60}$ e Demea, a religião deveria exercer o papel de conforto existencial, o que para Hume não é possível.

\section{Religião e Superstição}

Como já fora dito, este tipo de raciocínio não pode estar ligado à religião de forma alguma, por se tratar de um tipo de conhecimento que tenta lidar com questões que estão além de nossas capacidades. Nem mesmo uma genealogia da religião apresenta qualquer forma de justificação para sua tentativa investigativa obscura e abstrusa, fazendo com que Hume associe qualquer uma dessas tentativas de justificação da religião a um tipo de superstição. Neste sentido, o filósofo escocês apresenta críticas às tentativas da religião de justificar alguma de suas crenças como sendo racionais e demonstráveis ou ainda autoevidentes.

Um problema crucial para Hume é apresentado na secção X das Investigações e trata da questão dos milagres, cuja importância, para o filósofo, está no fato das religiões se basearem em milagres para sustentar suas doutrinas ${ }^{61}$, ou seja, as doutrinas religiosas não têm uma justificação plausível, pois como acreditar em algo cujo fundamento é improvável? Contudo, apresentemos primeiramente a discussão proposta por Hume.

Devemos, primeiro, caracterizar o milagre para Hume ${ }^{62}$ como: a) "uma violação das leis da natureza" b) que nunca tenha ocorrido no curso da história. Neste sentido, um milagre é extraordinário, no sentido etimológico do termo.

Outro ponto fundamental para Hume é definir a diferença entre crer em um testemunho e crer em uma experiência. Um testemunho é uma narrativa de alguém acerca de algo passado que se baseia na conexão necessária e na confiança

\footnotetext{
${ }^{60}$ Cf. Ibid., pp. 94 e 141.

${ }^{61}$ Várias críticas podem ser apresentadas a este tipo de interpretação do milagre à luz da religião, uma vez que Hume confunde milagre e revelação. Mas este não é o propósito do presente trabalho. ${ }^{62}$ Cf. HUME, Investigações..., p. 176.
} 
no narrador. Quando o testemunho é variável, ele é provável; quando é constante, ele é prova. Neste sentido, uma crítica à ideia de conexão necessária faz com o testemunho perca muito de sua força, o que de fato Hume acredita, pois ele mostrara que não haveria conexão necessária. Já uma experiência baseia-se nos sentidos que, mesmo podendo nos enganar, fornecem um "certo critério" para sabermos o que é mais provável, tendo em vista a análise de fatos contraditórios $^{63}$, logo, é muito mais fácil uma experiência ser prova do que um testemunho.

Dados esses pressupostos, analisemos a crença em um milagre, tendo em vista justificar sua existência, caso seja possível. É muito mais fácil crermos em algo com que estamos acostumados do que crer em algo novo, pois o costume faz com que haja facilidade na transição de uma ideia para uma impressão, sendo esta mais viva, logo, a crença, que é um sentimento, se torna mais forte. Quando um fato é novo não há essa operação de transição o que faz com que a crença nesse fato perca sua força, logo, "autoridade".

Como um milagre é algo sempre novo, pelo ponto b) da definição, crer em um milagre apresenta um aspecto atenuador da crença: falta de costume com o fato que não aviva nossa crença ${ }^{64}$. O ponto a) da definição apresenta outro aspecto negativo, para Hume. Se um milagre é uma violação das leis da natureza, então sua ocorrência é contrária a todo o "testemunho" - no sentido lato do termo - da história, pois a uniformidade da natureza forma uma prova direta e cabal, como afirma o filósofo escocês da supracitada passagem das Investigações, contra todo fato milagroso.

Hume apresenta como que um cálculo simples: dados dois fatos com forças diferentes, a nossa crença final será o resultado da soma dessas forças. Se forem contrárias, então o que resultado será uma subtração, prevalecendo a crença que tiver a maior força. Desde modo, crer em um milagre se baseia em algo provável, enquanto crer na uniformidade da natureza é crer em uma prova constante. Nesta soma, o fato milagroso sempre terá menos peso, o que faz com que a crença neste seja mais improvável do que a crença naquela. Assim, "a consequência clara disso tudo (...) é que: 'Nenhum testemunho basta para estabelecer um milagre, a não ser que seja de tal índole, que sua falsidade seria mais milagrosa do que o próprio fato que procura estabelecer (...)" ${ }^{\text {" } 65}$, porque

\footnotetext{
${ }^{63}$ Ibid., p. 174.

${ }^{64}$ Lembremos que o mesmo raciocínio vale para a moral e a influência das crenças religiosas em nós. Como estas são distantes e não experienciáveis, sua influência é muito pequena, tendo em vista avivar nossas crenças e impulsionar ações em nós.

${ }^{65}$ HUME, op. cit., p. 177.
} 
deste modo, ao "pesar" dois fatos milagrosos - o fato a afirmar e a sua negação que deve ser também milagrosa, por definição - o que for menos provável será descartado, ou seja, se a negação de um fato milagroso for mais milagroso, então esta negação será menos provável, fazendo com o que fato milagroso prevaleça como crença. Mas Hume não acredita que seja possível haver um fato milagroso cuja negação é mais improvável.

Além disso, Hume apresenta mais quatro problemas ${ }^{66}$ relativos aos testemunhos dos milagres, dos quais falaremos seguindo a exposição de Gaskin: 1) as evidências empíricas não foram satisfeitas; 2) o homem gosta do extraordinário, podendo gerar uma paixão maior e fazendo com que se dê mais crédito ao milagre que às leis da natureza - o que não tem fundamento científico para Hume; 3) os milagres só acontecem entre os bárbaros e não entre os sábios, fazendo com que sejam menos confiáveis e 4) há várias contradições entre milagres de várias religiões, o que desacredita ainda mais pode ter havido um fato milagroso. Hume conclui que para haver um milagre a humanidade como um todo deveria constatar o mesmo fato da mesma maneira em sua ocorrência no mundo.

Gaskin $^{67}$ afirma que Hume não conclui que é impossível haver um milagre, mas que é muito pouco provável. Na verdade, o filósofo escocês, pela sua definição de milagre, teria alguns problemas para explicar o inusitado na ciência, mas não é este o ponto desta discussão. O que vale notar é que Hume mostra, no Investigações, uma postura cético-limitadora acerca do conhecimento e da justificação humana.

No livro História Natural da Religiãa $0^{68}$, o autor apresenta uma evolução marcadamente antropológica - nos dizeres contemporâneos - da religião. Hume a descreve como sendo um processo humano, cuja origem e estabelecimento remontam e coincidem com a própria superstição e falta de desejo investigativo.

Assim, segundo Hume, a falta de vontade de haver uma investigação mais rigorosa, fez com que a humanidade não se apegasse à explicações racionais, mas à superstições ligadas às vicissitudes. Outro problema está no fato de as causas e as fontes do mundo estarem escondidas, o que faz com que haja confusão na concepção de suas ideias, desestimulando uma investigação propriamente filosófica ${ }^{69}$. Com isso, surgem inúmeras explicações baseadas em

\footnotetext{
${ }^{66}$ Ibid., pp. 177-179.

${ }^{67}$ Cf. GASKIN, Hume 's Philosophy..., pp. 116-119; 120-125.

${ }^{68}$ Cf. HUME, História Natural..., pp. 154-155.

${ }^{69}$ Cf. Ibid., pp. 161-167.
} 
crenças extravagantes e infundadas, o que se caracteriza por uma superstição e não um conhecimento de fato. Com isto, Hume conclui que seria impossível que a humanidade tivesse começado apresentando características religiosas monoteístas, por estas serem mais elaboradas, logo, na antiguidade só pode ter havido politeísmos $^{70}$. Mesmo o "avanço" ${ }^{\text {"71 }}$ para o teísmo ocorreu não por questões de esclarecimentos, mas superstições ainda maiores, o que acarreta uma má religião, de tal modo que mesmo com o avanço da investigação humana há sempre um "fluxo" e "refluxo" entre politeísmo e teísmo ${ }^{72}$, influenciado pela presença constante de crenças infundadas, logo, supersticiosas.

Se, por um lado, no politeísmo a investigação não existe e acaba por gerar inúmeras confusões obscuras, por outro, no teísmo, apesar de haver mais procura por uma investigação racional, esta mesma investigação se dirige a questões que estão além da possibilidade e capacidade humanas ${ }^{73}$.

\section{Conclusão}

Não resta dúvida que em nenhuma instância há um fundamento racional para a religião. Nem mesmo a prática religiosa, para o filósofo escocês, se baseia na consciência, mas na mesma superstição. Não buscamos a Divindade porque queremos alcançar uma prática moral, mas para bajulá-la. O ser humano acaba justificando tudo - moral, crença, suposições metafísicas e epistemológicas - pela atitude supersticiosa.

Gaskin $^{74}$ chega a afirmar que Hume quer romper com esse tipo de superstição, que ele chama de vulgar, utilizando as palavras do próprio Hume. Assim, o filósofo escocês não afirma simplesmente que todo tipo de religião é obscura e supersticiosa, mas que um homem sábio procura evidências para sua crença. Hume já havia enunciado isto na discussão acerca dos milagres, no Investigações. O problema é que grande parte da religião em sua genealogia, no fundamento de suas crenças e na base de suas explicações tem optado por fundamentos além da razão o que gera grande confusão, crenças esdrúxulas e corrupção.

\footnotetext{
${ }^{70}$ Cf. Ibid., pp. 152-153.

${ }^{71}$ Vale notar que, para Hume, a passagem do politeísmo para o teísmo se caracteriza por um avanço do "inferior para o superior" (Ibid., p. 154).

${ }^{72}$ Hume cita o exemplo da criação de divindades intermediárias para nos fazer comunicar melhor com Deus, por exemplo, os santos e Nossa Senhora para os católicos. Cf. Ibid., p. 190-193.

${ }^{73}$ Cf. Ibid., pp. 202-203; 229-231.

${ }^{74}$ Cf. GASKIN, Hume's Philosophy..., pp. 143-146.
} 


\section{Referências Bibliográficas}

HUME, David. The Treatise of Human Nature. London, UK: Penguin Classics, 1985 [1739-1740].

. Investigação sobre o Entendimento Humano. São Paulo, SP: Abril Cultural, 1973 [1748]. (Coleção Os Pensadores, vol. 22).

. Diálogos sobre a Religião Natural. In: Obras sobre Religião. Lisboa: Fundação Calouste Gulbenkian, 2005 [1779].

. História Natural da Religião. In: Obras sobre Religião. Lisboa:

Fundação Calouste Gulbenkian, 2005 [1757].

BENNETT, Jonathan. Learning from six Philosophers. Vol. 2. USA: Oxford University Press, 2003.

DICKER, Georges. Hume's Epistemology and Metaphysics. London, UK: Routledge, 1998.

FOGELIN, Robert J. Hume`s scepticism. In: NORTON, David F. (Ed.). The Cambridge Companion to Hume. Cambridge, UK: Cambridge University Press, 1998.

GASKIN, J.C.A. Hume`s Philosophy of Religion. 2 ed. London: The Macmillan Press Ltd., 1988.

HONDERICH, Ted (Ed.). The Oxford guide Philosophy. New York, USA: Oxford University Press, 2005.

NOXON, James. La evolución de la Filosofia de Hume. Madrid: Allianza Editorial, 1987.

O`CONNOR, David. Hume on religion. London, UK: Routledge, 2001.

ONFRAY, Michel. Tratado de Ateologia: fisica da metafísica. São Paulo: Martins Fontes, 2007.

RUSSELL, Paul. The Riddle of Hume's Treatise - Skepticism, Naturalism, and Irreligion. New York: Oxford University Press, 2008. Disponível em Oxford Scholarship Online <http://dx.doi.org/10.1093/acprof :oso/9780195110333.001.0001> Acesso em: 10 jun. 2009. 
SESSIONS, William L. Reading Hume`s Dialogues: a veneration for true religion. Bloomington, USA: Indiana University Press, 2002.

STROUD, Barry. Hume. London, UK: Routledge \& Kegan Paul Ltd, 1977.

Luis Felipe Lopes Doutorando em Filosofia pela Universidade Federal de Minas Gerais (UFMG) na área Filosofia Moderna, com ênfase em filosofia da religião, epistemologia, metafísica e filosofia moderna

E-mail: servusmatris@hotmail.com

Recebido em 25/11/12

Aprovado em 14/05/13 